\section{Inculturación de la teología en Gregorio de Nisa: antecedentes $^{*}$}

\author{
ORLANDo SOLANo Pinzón ** \\ RECIBO: 13-06-14 - APROBACIÓN: 11-11-14
}

Resumen: Da razón de los antecedentes del trabajo de inculturación de la teología en Gregorio de Nisa. Además de una breve aclaración conceptual, hace un acercamiento a su experiencia vital, indagando sobre los elementos que fueron fraguando su fe y sobre el esfuerzo de dar razón de la misma mediante su labor teológica y pastoral, en el contexto de la cultura de su tiempo.

Palabras clave: Patrística, Gregorio de Nisa, inculturación, teología.

PARA CITAR ESTE ARTÍCULO:

Solano Pinzón, Orlando. "Inculturación de la teología en Gregorio Nisa: antecedentes." Theologica Xaveriana 179 (2015): 157-183. http://dx.doi.org/ 10.11144/javeriana.tx65-179.itgn
Theological Enculturation in Gregory of Nyssa: background

Aвstract: It reports the antecedents of the enculturation of Theology by Gregorio de Nisa. Besides providing a brief conceptual clarification, it approaches his vital experience, by investigating the items that built his faith and his effort to justify it, through his theological and pastoral labor, in the context of the culture of his time.

KeY words: Patristic study, Gregory of Nyssa, enculturation, theology.

\section{Enculturação da teologia em Gregório de Nisa: antecedentes}

Resumo: Trata do tema dos antecedentes do trabalho de enculturação da teologia em Gregório de Nisa. Além disso, parte de um breve esclarecimento conceitual para fazer uma aproximação à sua experiência vital, indagando sobre os elementos que foram forjando sua fé, e sobre o esforço de dar razáo à mesma mediante seu labor teológico e pastoral, no contexto da cultura de seu tempo.

palavras-chave: Patrística, Gregório de Nisa, enculturação, teologia.

*El presente escrito corresponde a un fragmento de la investigación "Inculturación de la teología. Aportes desde la paideia cristiana en el De vita Moisis de Gregorio de Nisa”, realizada para optar por el título de Doctor en Teología, en la Pontificia Universidad Javeriana.

** Doctor, Magister y Profesional en Teología, Pontificia Universidad Javeriana, Bogotá; Licenciado en Filosofía, Universidad Santo Tomás, Bogotá. Docente de tiempo completo, Facultad de Teología, Pontificia Universidad Javeriana; miembro del grupo de investigación Academia. Correo electrónico: o.solano@javeriana.edu.co 


\section{Introducción}

Los padres de la Iglesia son reconocidos como modelos de inculturación del cristianismo ${ }^{1}$ en el sentido de repensarlo en el ambiente cultural greco-romano. Este trabajo de inculturación adquiere gran variedad de matices porque está marcado por la historia personal de quien lo realiza, de modo que no es posible predicar lo mismo para todos los autores, aunque de su trabajo escriturístico se pueda afirmar que hace parte de la inculturación de la teología en la Antigüedad.

El presente artículo tiene como objetivo identificar las características y los ejes fundamentales que orientaron la labor de inculturación del quehacer teológico de Gregorio de Nisa en la cultura griega, y permiten a su vez comprender mejor su obra literaria. Para efecto de procedimiento, haremos una breve aclaración conceptual y posteriormente situaremos los antecedentes en dos momentos: el primero, los antecedentes remotos referidos a las características de su lugar de nacimiento, su núcleo familiar, su educación, hasta el ejercicio de su profesión como rétor; y el segundo, los antecedentes próximos, en los cuales se ubica su renuncia a la labor de rétor y el posterior desplazamiento al monasterio del Ponto con su hermano Basilio, el estudio profundo de las Escrituras y las obras de Orígenes, la elección como obispo y el desarrollo de su ministerio, y el despliegue de su trabajo escriturístico en cuyos inicios incidió su hermano.

\section{Noción de inculturación de la teología}

Antes de abordar el concepto inculturación de la teología conviene hacer una referencia a los términos cultura y teología, pues hay una amplia variedad de significados. En cuanto al concepto cultura, el presente trabajo comparte la diferenciación que establece Lonergan entre la concepción clásica (concebida de forma normativa y, por tanto, no hay sino una cultura) y la concepción empírica (que reconoce la existencia de muchas culturas). ${ }^{2}$

${ }^{1}$ Ver Congregación para la Educación Católica, "Instrucción sobre el estudio de los padres de la Iglesia" Nos. 34-43.

${ }^{2}$ Lonergan, Metodo en teología, 9. 
Sobre este primer acercamiento conviene afirmar que la investigación asume la comprensión empírica de cultura ${ }^{3}$, esto es, se reconoce la diversidad cultural, pues se ajusta a la realidad que es propia de la naturaleza humana. ${ }^{4}$

En lo que respecta a la definición de cultura, se asume la planteada por Marcelo de Carvalho Azevedo, en Comunidades eclesiais de base e inculturação da fé, compartida por Mario de Franca, en La inculturación de la fe. Un abordaje teológico, pues permite relacionarla con la comprensión empírica de cultura a la que antes se ha hecho referencia. Afirman estos autores:

Cultura es el conjunto de sentidos y significados, de valores y patrones, incorporados y subyacentes a los fenómenos perceptibles de la vida de un grupo social concreto, conjunto que, consciente o inconscientemente, es vivido y asumido por el grupo como expresión propia de su realidad humana y pasa de generación en generación, conservando así como fue recibido o transformado efectiva o pretendidamente por el mismo grupo. ${ }^{5}$

La definición anterior permite entender que, si bien el hombre crea cultura, esta a su vez le permite realizarse como un ser verdaderamente humano. ${ }^{6}$ Además, es posible inferir que la cultura existe a través de las culturas. De allí el carácter de unidad y diversidad que Edgar Morín atribuye a la cultura en el siguiente sentido: "La cultura mantiene la identidad humana en lo que tiene de específico; las culturas mantienen las identidades sociales en lo que ellas tienen de específico."

A partir del acercamiento realizado a la noción de cultura, pasamos ahora a comentar el término inculturación, aclarando que aunque dicha categoría es un neo-

\footnotetext{
${ }^{3}$ Esta comprensión empírica de cultura está presente en los documentos del Vaticano II; particularmente, la Gaudium et spes reconoce la pluralidad de culturas, esto es: "Estilos de vida común diversos y escalas de valor diferentes que encuentran su origen en la distinta manera de servirse de las cosas, de trabajar, de expresarse, de practicar la religión, de comportarse, de establecer leyes e instituciones jurídicas, de desarrollar las ciencias, las artes y de cultivar la belleza." (Concilio Vaticano II, "Constitución pastoral Gaudium et spes sobre la Iglesia en el mundo moderno", No. 53).
}

${ }^{4}$ Morín, Los siete saberes para la educación del futuro, 22-28.

${ }^{5}$ Azevedo, Comunidades eclesiais de base e inculturação da fe, 336; la misma cita es retomada y asumida por De França, La inculturación de la fe: un abordaje teológico, 70.

${ }^{6} \mathrm{Al}$ respecto, el Concilio Vaticano II, en la Gaudium et spes, es claro al afirmar: "Es propio de la persona humana el no llegar a un nivel verdadera y plenamente humano si no es mediante la cultura, es decir, cultivando los bienes y los valores naturales. Siempre, pues, que se trata de la vida humana, naturaleza y cultura se hallen unidas estrechísimamente." (Concilio Vaticano II, "Constitución pastoral Gaudium et spes", No. 53.

${ }^{7}$ Morín, Los siete saberes para la educación del futuro, 31. 
logismo que entró a formar parte del lenguaje oficial eclesiástico en la segunda mitad del siglo XX, la problemática que está en la base de la misma ha estado presente a lo largo de toda la historia de la Iglesia. ${ }^{8}$ En este sentido -según Poupard ${ }^{9}$ - el Concilio de Jerusalén narrado en Hechos de los Apóstoles es prueba de la siempre presente necesidad de inculturar la fe y la teología.

Concretamente, desde 1978, con ocasión de un Sínodo sobre catequesis ${ }^{10}$, abordó el tema el padre Arrupe, quien comentó las razones de la inculturación al asumirla en clave de encarnación.

La inculturación es la encarnación de la vida y del mensaje cristianos en un espacio cultural concreto, de suerte que no solo esta experiencia se exprese con los elementos propios de la cultura en cuestión, sino que esta misma experiencia se transforme en un principio de inspiración, norma y fuerza de unificación a la vez, que transforme y recree esta cultura, para situarnos en el origen de una nueva creación. ${ }^{11}$

Este énfasis referido a la encarnación fue retomado por Nicolás Standaert, en un artículo titulado " $L$ 'histoire d'un néologisme. Le terme 'inculturation' dans les documents romains". En él describe dos maneras de comprender el término inculturación en los documentos eclesiales: como adaptación ${ }^{12}$ y como encarnación.

Particularmente, Standaert deja al descubierto la insuficiencia de la adaptación, pues se limita a una función de traducción, y considera oportuno apropiar la inculturación como encarnación, ya que al tener como referente el misterio de la encarnación ${ }^{13}$ como dinamismo remite a la inserción, enraizamiento, integración y

${ }^{8}$ Ver a Poupard, "Los padres de la Iglesia: actualidad de una inculturación de la fe", 28-29.

${ }^{9}$ Sobre esta dinámica de inculturación, el mismo Poupard afirma: "Aun cuando el término inculturación entró a formar parte del lenguaje oficial eclesiástico hace muy poco tiempo, la problemática de la inculturación está presente a lo largo de toda la historia de la Iglesia." (Poupard, "Los padres de la Iglesia: actualidad de una inculturación de la fe", 29).

${ }^{10}$ Moreno Martínez, La luz de los padres. Temas patrísticos de actualidad eclesial, 143-144.

${ }^{11}$ Citado por Laurent, Iniciación a la práctica de la teología. La práctica, acciones pastorales, 239.

${ }^{12} \mathrm{Al}$ entender la inculturación como adaptación se incurre en lo que Edgar López señala como "óptica unilateral e invasiva que aparenta ser garante de la unidad, pero que en realidad no favorece la comunión" (López, La evangelización como práctica interpretativa, 46).

${ }^{13}$ Sobre este tema, la Gaudium et spes se expresa en los siguientes términos: "Múltiples son los vínculos que existen entre el mensaje de salvación y la cultura humana. Dios, en efecto, al revelarse a su pueblo hasta la plena manifestación de sí mismo en el Hijo encarnado, habló según los tipos de cultura propios de cada época."(Concilio Vaticano II, "Constitución pastoral Gaudium et spes"No. 58). 
apropiación, sin excluir las posibles limitantes que pueden surgir del diálogo con las culturas y la referencia al lenguaje.

Además, el aporte fundamental y punto de partida de la inculturación, entendida en términos de encarnación, remite a reconocer que no conocemos todavía a Cristo en su plenitud, y que es gracias a la manera como una cultura experimenta y realiza los desafíos del Evangelio que otras culturas ya cristianas pueden convertirse y renacer a una imagen cada vez más pura de Cristo. ${ }^{14}$

En relación con lo anterior, es posible afirmar con Rovira Belloso que "el criterio de la encarnación (que incluye la creación) puede tomarse no como un criterio entre muchos, sino como el criterio rector de todo el proceso de inculturación". ${ }^{15}$

Tras este ejercicio de aclaración de términos, pasamos ahora a describir la comprensión del concepto teología que se maneja en la presente investigación. Debido a la multiplicidad de definiciones que se han proferido sobre el término en cuestión ${ }^{16}$, y dada la necesidad de concretar nuestra comprensión al respecto, concebimos la teología, más que por la semántica del término, por las características que ha asumido a lo largo de los siglos.

Por ello, al hablar de teología hacemos referencia a la función mediadora entre una determinada matriz cultural y el significado y valor de la religión en dicha matriz ${ }^{17}$, al marcado acento histórico sobre el cual se elabora y el dato de fe que le confiere su especificidad ${ }^{18}$, en términos de reflexión crítica de la praxis histórica a la luz de la $\mathrm{fe}^{19}$ y al carácter existencial, ético, espiritual, reflexivo, crítico, lingüístico, doctrinal y celebrativo que involucra el encuentro con Dios que envuelve la totalidad de la existencia, el sentimiento, el corazón, la inteligencia y la voluntad. ${ }^{20}$

A partir de las características antes descritas, podemos entender la inculturación de la teología en clave de encarnación como el proceso de apropiación de una matriz

\footnotetext{
${ }^{14}$ Standaert, "L'histoire d'un néologisme. Le terme 'inculturation' dans les documents romains”, 555-570.

${ }^{15}$ Rovira Belloso, Introducción a la teología, 326.

${ }^{16}$ Sobre esta afirmación da razón el libro de Libanio y Murad, Introducción a la teología. Perfiles, enfoques, tareas, en el cual se enuncian 19 definiciones de teólogos reconocidos.

${ }^{17}$ Lonergan, Método en teología, 9.

${ }^{18}$ Particularmente Heidegger concibe la experiencia de fe como el positum de la teología, que permite concebirla como ciencia positiva. Para él, "la teología es la ciencia de la fe no solo en la medida en que convierte en objeto a la fe y a lo creído, sino porque ella misma nace de la fe. Es la ciencia que la fe motiva y justifica desde sí misma” (Heidegger, "Fenomenología y teología”, 57).

${ }^{19}$ Gutiérrez, Teología de la liberación, 34.

${ }^{20}$ Libanio y Murad, Introducción a la teología, 106.
} 
cultural, para repensar, decir, vivir y celebrar desde ella, la manera como se desoculta Dios en los acontecimientos de la historia que viven las mujeres y los hombres que comparten dicha matriz. ${ }^{21} \mathrm{Si}$ bien el lenguaje mediante el cual se recibe y expresa el desocultarse de Dios siempre se queda corto, pueden de manera analógica hacerse acercamientos provisorios, debido a que el lenguaje humano ${ }^{22}$ está abierto a hacer presente y comunicar una realidad que lo trasciende. ${ }^{23}$

\section{Antecedentes remotos de la inculturación de la teología en Gregorio de Nisa}

\section{Contexto sociopolítico y económico de la Capadocia de la segunda mitad del siglo IV}

El siglo IV, denominado Siglo de Oro, representa tanto el fin de un mundo como el nacimiento de otro, en el cual se imbrican diferentes puntos de vista, político, económico, cultural y religioso. ${ }^{24}$ De Roma, abandonada y vieja, a la nueva Constantinopla; de la civitas al señorío; del barroco tardo-romano al bizantino arcaico; del fin de las persecuciones al Imperio cristiano. Este es un cambio que no pasa desapercibido en una familia de políticos y abogados, como es la de Gregorio, con historia de servicios imperiales y excelentes relaciones públicas. ${ }^{25}$

Geográficamente, Capadocia es una región montañosa de Asia Menor que desciende, de sur a norte, desde las cumbres del Tauro, que la separa de la Cilicia (Tarso)

${ }^{21}$ La apropiación de la matriz cultural es esencial en el proceso de inculturación debido a que -como señala Robira Belloso- "una cultura solo puede ser fecundada desde dentro, desde su libertad, no desde fuera y desde el dominio exterior ejercido con medios puramente humanos" (Rovira Belloso, Introducción a la teología, 327). La cursiva es mía y busca evidenciar la referencia que hace Rovira a la constitución pastoral Gaudium et spes No. 42.

${ }^{22}$ No en vano Heidegger comprende el lenguaje básicamente como el medio privilegiado en el que se despliega la referencia del ser al hombre. En este sentido se sitúa su famosa frase: "El lenguaje es la casa del ser. En su morada habita el hombre." (Heidegger, Carta sobre el humanismo, 7).

${ }^{23}$ Es por ello que Víctor Codina, en su estudio sobre la teología oriental, sostiene que para Oriente la mística, que es a su vez reflexiva, lúcida e inteligente, es la cumbre de la teología; más aún, la palabra teología, que significa la escritura que nos revela el misterio de Cristo, culmina en la contemplación y participación de la vida trinitaria (Codina, Los caminos del Oriente cristiano. Iniciación a la teología oriental, 32).

${ }^{24}$ En este momento histórico, la región de la Capadocia se encuentra totalmente helenizada y cristianizada (Blázquez, "La Academia de Atenas como foco de formación humanística para paganos y cristianos. Los casos de Juliano, Basilio y Gregorio Nacianceno", 597).

${ }^{25}$ Kopecek, "The Social Class of the Cappadocian Fathers", 461-466. 
y Siria (Antioquía), hacia las costas del Mar Negro, en el Ponto, mientras que de este a oeste se recorta entre el Eúfrates y las regiones de Licaonia y Galacia. Lo accidentado de su entorno geográfico hizo de la región un lugar privilegiado para el refugio, el retiro, la meditación o el trabajo intelectual ${ }^{26}$ evidenciado en el realizado por los capadocios.

En su historia, Capadocia había sido hitita casi un milenio; luego fue persa, alejandrina -razón por la cual fue de helenización tardía- y, desde el siglo II a.C., romana, esto es, reino federado primero y provincia imperial con Tiberio. La administración romana había organizado este pueblo sirio ("sirios blancos", al decir de los persas), de población más bien dispersa, en tres provincias: Ponto, Armenia y Capadocia. ${ }^{27}$

Gregorio había nacido en Cesarea, la capital de Capadocia, aproximadamente entre los años 331 y $335 .{ }^{28}$ Por línea paterna descendía de una familia de antigua raigambre cristiana, originaria del Ponto, que había sufrido la persecución por confesar la $\mathrm{fe}^{29}$; y por la línea materna, de una familia de Capadocia que destacaba en la vida militar y civil. ${ }^{30}$

Sus padres se llamaban Emelia y Basilio, y este último ejercía la labor de rétor ${ }^{31}$, profesión que Gregorio también asumiría. Fue el cuarto entre diez hermanos, de los cuales tres son también reconocidos como santos: Santa Macrina, San Basilio y San Pedro de Sebaste. En la región de Cesarea de Capadocia, su familia poseía numerosas propiedades ${ }^{32}$, entre las cuales se encontraba la finca de Annesi, lugar al cual se retiraron la madre, varios hermanos y siervos, para apropiar una vida monástica en torno de Macrina. ${ }^{33}$

${ }^{26}$ Torres Moreno, San Gregorio de Nisa. "De Vita Moysis": estudio estructural, 31-32.

${ }^{27}$ Balderas Vega, Jesús, cristianismo y cultura en la Antigüedad y en la Edad Media, 186.

${ }^{28}$ Sobre la fecha del nacimiento y la muerte no hay unidad de criterios entre los autores, razón por la cual de manera tentativa señalamos el periodo comprendido entre los ańos 331 y el 335, para el nacimiento, y 394 y 397 , para su muerte.

${ }^{29}$ No en vano Ramos señala que "el siglo IV, como ninguno antes ni ninguno después, es el siglo de la búsqueda de Dios" (Ramos Jurado, "Paideia griega y fe cristiana en Sinesio de Cirene", 251.

${ }^{30}$ Ver Patrologia graeca 36, 497 C.

${ }^{31}$ Trevijano Etchevarria, Patrología, 206.

${ }^{32}$ La evidencia sobre las posesiones es posible rastrearla en el libro Vida de Macrina, en el cual Gregorio afirma: "Sa mère, qui avait quatre fils et cinq filles et payait l'impôt à trois gouverneurs, ses biens se répartissant en autant de provinces." (Grégoire de Nysse, Vie de Sainte Macrine, 159; 161).

${ }^{33}$ Quasten, Patrología II. La edad de oro de la literatura patrística griega, 282-283; Mateo-Seco, Gregorio de Nisa. Sobre la Vida de Moises, 9; Moreschini, I Padri Cappadoci, storia, letteratura, teología, 28. 
La educación de Gregorio estuvo orientada, en sus primeros años, por sus padres y su hermana Macrina; posteriormente al regreso de Basilio de su estadía en Atenas, se encargó de guiar la educación de su hermano, y además de orientarlo en el estudio de autores clásicos, le puso en comunicación con el rétor Libanio. Por aquella época, la fuerza que tenía la profesión de rétor logró hacer mella en Gregorio, al punto de llevarle a abandonar el ministerio como lector en su parroquia y, durante ese tiempo, contraer matrimonio con Teosebia. ${ }^{34}$ Ambos compartían las mismas inclinaciones espirituales y permanecieron unidos hasta que ella falleció, lo cual ocurrió muy temprano. ${ }^{35}$

Gregorio se desempeñó por un tiempo como profesor de Retórica, pero animado por su familia y sus amigos, en especial por quien luego sería San Gregorio Nacianceno ${ }^{36}$, se retiró al monasterio de Iris, en el Ponto, para dedicarse a prácticas ascéticas y al estudio de la teología. Su vida se movió en torno de su Capadocia natal, de la que se apartó solo durante algunos viajes sinodales y un breve exilio en Armenia. ${ }^{37}$

\section{Contexto eclesiástico}

Según José Orlandis, cuando el siglo IV comenzó, el cristianismo era apenas tolerado por el Imperio, alcanzó luego un estatuto de libertad y se convirtió finalmente, en tiempo de Teodosio, en religión oficial. El emperador romano-cristiano convocó los concilios de la época y la Iglesia pudo organizar sus estructuras territoriales de gobierno pastoral. ${ }^{38}$

Según Daniélou ${ }^{39}$, el Imperio estaba dividido en diócesis con la misma composición de las provincias; de esta manera, en cada ciudad en la cual había un defensor y una curia, se estableció un obispo que gobernase en lo espiritual con la ayuda

\footnotetext{
${ }^{34}$ Daniélou, "Le mariage de Gregoire de Nysse et la chronologie de sa vie”, 72-78; Idem, "La chronologie des oeuvres de Gregoire de Nysse", 56.

${ }^{35}$ Daniélou, "Le mariage de Gregoire de Nysse et la chronologie de sa vie", 71-78; Argüello, Caminar con los padres de la Iglesia, 75. Sobre este tema del matrimonio de Gregorio no hay unidad de criterios entre los estudiosos, pues la referencia al nombre de Teosebia es problemática debido a que ese era también el nombre de una de sus hermanas. Para mayor información sobre este tema, ver a Silvas, Gregory of Nyssa: The Letters. Introduction, Translation and Commentary, 15-18.

${ }^{36}$ Gregorio de Nacianzo le envía una carta para llamar su atención e invitarle a volver nuevamente, y unirse a la experiencia monacal que había formado su hermano Basilio. Ver a Silvas, Gregory of Nyssa: The Letters, 91.

${ }^{37}$ Malherbe y Ferguson, Gregory of Nyssa. The Life of Moses, xiv-xv.

${ }^{38}$ Orlandis, Historia breve del cristianismo, 36.

${ }^{39}$ Daniélou, Le IV siecle. Gregoire de Nysse et son milieu, 12.
} 
de los presbíteros. En cada capital de provincia se estableció un metropolitano, y en cada capital de diócesis, un patriarca.

Esta estructura organizativa contribuyó al desarrollo de la ciencia eclesiástica, junto a otros factores: el ambiente de paz que, poco a poco, se fue consolidando en el Imperio, al convertirse el cristianismo en la religión del Estado y la Iglesia en Iglesia imperial, y la resistencia a la herejía, particularmente la arriana ${ }^{40}$, que generó divisiones internas.

En este desarrollo asumieron un papel preponderante los padres capadocios, quienes además contribuyeron al nacimiento del monacato e hicieron parte de las grandes disputas doctrinales, especialmente la trinitaria. ${ }^{41}$ Sobre el tema de las disputas, en principio fue Basilio quien tomó las banderas de Atanasio, en la defensa de la fe de Nicea, enfrentándose a los arrianos; posteriormente, tras la muerte de Basilio, lo hizo su hermano Gregorio, quien junto con Gregorio de Nacianzo cumplieron un papel determinante en la derrota final del arrianismo en el Concilio de Constantinopla, en 381.42

El papel que cumplieron los capadocios, y con ellos, nuestro autor, Gregorio de Nisa, se comprende mejor al conocer la función preponderante que adquirió la figura del obispo al interior de la Iglesia y de la sociedad. Ramón Teja, especialista en la historia y la literatura antiguas, señala que el mundo greco-romano dio lugar a variedad de figuras que dinamizaron la civilización antigua, entre ellas, el político, el sacerdote, el jurista, el filósofo, el rétor, etc. Entre estas figuras no es posible parangonar al obispo, aunque en el plano social asuma un poco de cada una de ellas. ${ }^{43}$

En correspondencia con lo anterior es posible afirmar que el poder episcopal se ubicó, tanto a nivel ideológico como a nivel operativo, en el mismo nivel que el poder político. ${ }^{44}$ Este prototipo de obispo que se consolidó en la Capadocia del siglo IV permite comprender mejor las razones que llevaron a Basilio - una vez elegido obispo

\footnotetext{
${ }^{40}$ La herejía arriana tomó su nombre de Arrio (256-336), sacerdote de Alejandría y después obispo libio, quien desde 318 propagó la idea de que no hay tres personas en Dios, sino una sola: el Padre. Según Arrio, Jesucristo no era Dios, sino había sido creado por Dios de la nada, como punto de apoyo para su plan. El Hijo es, por tanto, criatura, y su ser de hijo tiene un principio; ha habido, por tanto, un tiempo en que él no existía. Al sostener esta teoría, Arrio negaba la eternidad del Verbo, lo cual equivale a negar su divinidad. Según Arrio, a Jesús se le puede llamar Dios, pero solo como una extensión del lenguaje, por su relación íntima con Dios (Llorca, Historia de la Iglesia Católica. Edad Antigua, 384-387).

${ }^{41}$ Ibid., 140.

${ }^{42}$ Daniélou, Le IV siecle, 5-7.

${ }^{43}$ Teja, Emperadores, obispos, monjes y mujeres, protagonistas del cristianismo antiguo, 75.

${ }^{44}$ Ibid., 78.
} 
de la sede metropolitana de Cesarea, en 370, y dado el conflicto que había con los obispos afectos al arrianismo ${ }^{45}$ - a ordenar como obispos a su hermano Gregorio, a su amigo Gregorio de Nacianzo y a Anfiloquio de Iconio, quienes por su vasta formación y elocuencia ${ }^{46}$ podían ayudarle, tanto en su defensa de la fe proclamada en Nicea, que había heredado de San Atanasio, como con la política eclesiástica iniciada tras su elección, para afianzar la unidad de la Iglesia. ${ }^{47}$

\section{Configuración de su experiencia de fe \\ Predicación de Gregorio Taumaturgo}

La presencia y la labor evangelizadora de Gregorio Taumaturgo ${ }^{48}$ fue un hecho que trascendió directamente en la familia de Gregorio de Nisa (particularmente en la conversión de sus abuelos) y que estuvo en la base de su experiencia de fe. Esto, por la incidencia que él tuvo en sus padres, al punto de ser el referente de inspiración del nombre de pila del Nisano.

Gregorio Taumaturgo había nacido en Neo-Cesarea, en el Ponto, en 213; su nombre era Teodoro, pero fue cambiado por Gregorio en el momento de celebrar su bautismo. ${ }^{49}$ Pertenecía a una noble familia pagana y quedó huérfano a los catorce años. En una ocasión fue invitado por su hermana -junto con su hermano Atenodoro- a Cesarea de Palestina, donde conocieron a Orígenes y, fascinados por sus enseñanzas, dejaron el estudio de derecho para dedicarse completamente a la filosofía y a la teología, como sus discípulos, durante cinco años. ${ }^{50}$

45 Según José Fernández Urbina, "el arrianismo tuvo en vilo a la Iglesia y al Imperio durante casi todo el siglo IV, particularmente en las provincias orientales, por motivos de hondo calado teológico que les llevaba a rechazar el trinitarismo niceno al identificarse con los postulados subordinacionistas que consideraban al Hijo inferior en mayor o menor grado al Dios padre. Dicho movimiento tendría luego una larga pervivencia en los reinos germánicos" (Fernández Urbina, Historia del cristianismo. Tomo I. Constantino y el triunfo del cristianismo en el Imperio Romano, 350-352).

46 “... la elocuencia era entonces la enseñanza más necesaria para triunfar en la vida eclesiástica y en la civil”; ańade el autor que "todas las ciudades de origen antiguo, no reciente, tienen algo de que enorgullecerse, por leyendas o por lo que se puede ver en ellas. Cesarea se distingue por la elocuencia, como seña de identidad cultural, que se opone a la fuerza de las armas o a la violencia de los espectáculos teatrales." (Blázquez, La Academia de Atenas como foco de formación humanistica para paganos y cristianos, 609).

${ }^{47}$ Teja, Emperadores, obispos, monjes y mujeres, 87; Quasten, Patrología II, 227, 262, 282.

${ }^{48}$ Este apelativo de Taumaturgo le viene por las acciones de curación que realizaba en el desarrollo de sus labores pastorales.

${ }^{49}$ Hamman, Para leer los padres de la Iglesia, 78.

${ }^{50}$ Quasten, Patrología I, Hasta el Concilio de Nicea, 185; Backhouse y Tyler, Historia de la Iglesia primitiva. Desde el siglo I hasta la muerte de Constantino, 296. 
Poco tiempo después, Gregorio recibió una carta de Orígenes en la cual le exhortaba a tomar de la filosofía griega aquellas cosas que pudieran ser conocimientos comunes o educación preparatoria para el cristianismo. ${ }^{51}$

Gregorio fue consagrado obispo de Neo-Cesarea por Fedimo, obispo de Amisos, y fue el primero en ocupar esta sede, en la cual permaneció unos treinta años. Sobre su actividad pastoral se forjaron numerosas leyendas referidas a sus milagros, que le merecieron el título de Taumaturgo. ${ }^{52}$

Fue un hombre de acción, eminente orador y gran misionero, a quien se reconoce como el fundador de la Iglesia en el Ponto y responsable de la conversión de Capadocia. Durante la persecución de Decio, Gregorio aconsejó a sus fieles que permanecieran lejos de los lugares objeto de persecución y que huyeran. En este grupo de personas estarían los abuelos de Gregorio de Nisa, quienes debieron huir a los bosques del Ponto. ${ }^{53}$ Entre sus discípulas se encuentra Santa Macrina la mayor, abuela de nuestro autor en cuestión, quien elaboró un panegírico en honor de este personaje. ${ }^{54}$

Gregorio Taumarugo tuvo una importancia definitiva como discípulo directo de Orígenes y padre espiritual de los capadocios, a quienes transmitió la influencia y la estima por el pensamiento de Orígenes. ${ }^{55}$

\section{Incidencia de Macrina, la hermana, y de Basilio, el hermano, sobre Gregorio}

Por las características señaladas, es claro que la familia de Gregorio de Nisa cumplió un papel muy importante en la manera como fue decantándose su vida, más aún, porque varios de sus miembros tuvieron una personalidad arrolladora, en especial, sus hermanos Macrina ${ }^{56}$ y Basilio. Tras la muerte temprana del padre, también llamado

\footnotetext{
${ }^{51}$ Grégoire le Thaumaturge, Remerciement a Origène suivi de la lettre d'Origène a Grégoire, 187-189. La traducción es nuestra.

52 Gregorio di Nissa, Vita di Gregorio Taumaturgo, 12-13; Moreschini, I Padri Cappadoci, 7.

${ }^{53}$ En el libro Vida de Macrina, Gregorio hace alusión a la situación de persecución que vivieron sus abuelos y la actitud de su abuela Macrina en los siguientes términos: "Une autre Macrine était depuis longtemps en grandrenom dans notre famille, la mère de notre père au temps des persécutions, elle avait lutté en confessant plusieurs fois le Christ." (Grégoire de Nysse, Vie de Sainte Macrine, 144-145).

${ }^{54}$ Moreschini, I Padri Cappadoci, 7, 13-14.

55 Grégoire le Thaumaturge, Remerciement a Origène suivi de la lettre d' Origène a Grégoire, 45.

${ }^{56}$ Macrina lleva el nombre de la abuela paterna, cuya labor continuará en la familia (Mateo Seco, Gregorio de Nisa, Sobre la Vida de Moisés, 11).
} 
Basilio, Macrina, mujer de profunda piedad, asumió -con su madre- el cuidado de sus hermanos y de las propiedades de la familia. ${ }^{57}$

Según Moreschini, los ideales ascéticos de la época ${ }^{58}$ explican las decisiones que la familia tomó después de la muerte del padre, ocurrida entre 340 y 342 . La formación religiosa tenía lugar en la catequesis eclesiástica y en la familia, como deber fundamental de los padres, pero en ausencia del padre, Macrina asumió dicha función con gran sentido de compromiso.

Aun cuando Gregorio vivió un momento de crisis después de su bautismo -que se dio en la etapa adulta y que le llevó a tomar la decisión de abandonar la labor de lector en su parroquia para dar paso a la profesión de rétor-, más adelante reconoció la importancia de su hermana, con quien permaneció en constante relación y a quien llamaba su maestra espiritual. ${ }^{59}$

Poco tiempo después de la muerte de Basilio, el padre, Macrina se retiró junto con su madre y algunos de sus hermanos y siervos a una propiedad familiar llamada Annesi, a la orilla del río Iris, para adoptar un modelo de vida monástica. ${ }^{60}$ Este lugar sería frecuentado ocasionalmente por Gregorio.

Igual que Macrina, Basilio -el hermano- también incidió en el proceso de fe de Gregorio, particularmente después de su regreso de Atenas, cuando ejerció su profesión de rétor. Al estar nuevamente en casa y movido por la influencia de su hermana mayor, Basilio decidió hacer un viaje por Egipto, donde entró en contacto con la experiencia de los monjes que vivían una vida de gran sacrificio, pero esta no logró llenar sus expectativas; por ello, a su regreso a Cesarea, se retiró a la propiedad de la familia y organizó una experiencia de vida monástica, a la cual se unieron su hermano Naucrancio, su amigo Gregorio de Nacianzo y el mismo Gregorio de Nisa, quien después de desistir de su profesión de rétor, pasó un tiempo en ese lugar. ${ }^{61}$

\section{La educación de Gregorio de Nisa}

Gregorio no estudió en Atenas y Constantinopla, como su hermano Basilio, pero contaba con una sólida formación proporcionada por su padre, quien era retórico de

\footnotetext{
${ }^{57}$ Ibid., 10.

${ }^{58}$ Moreschini, I Padri Cappadoci, 18.

${ }^{59}$ Campenhausen, Los padres de la Iglesia. I. Padres griegos, 147. Esta referencia a Macrina como maestra se explicita con claridad a lo largo de todo el tratado sobre el alma y la resurrección (Patrologiae graeca 46, 11-160).

${ }^{60}$ Hamman, Guía práctica de los padres de la Iglesia, 188.

${ }^{61}$ Moreschini, I Padri Cappadoci, 30.
} 
profesión; además, tras regresar de Atenas, Basilio asumió gran parte de la educación de su hermano, quien siempre le reconoció como maestro. ${ }^{62}$

Los hechos de que su padre fuese rétor, de que su hermano adelantase estudios de retórica en la escuela de Libanio, fuese un reconocido rétor, y de que la retórica fuese una disciplina obligada en la formación de todo joven que pretendiera adquirir una cultura superior, hizo que Gregorio mantuviese un gusto muy vivo por esta disciplina.

Desde el acercamiento a los estudios comunes de la época de Gregorio, es posible afirmar que estudió el ciclo de las ciencias clásicas y filosóficas, a Platón y Homero ${ }^{63}$, a los historiadores, y naturalmente, a los retóricos, que se le quedaron grabados para toda la vida. ${ }^{64} \mathrm{Su}$ curiosidad intelectual y su afán de saber le llevaron incluso a estudiar medicina ${ }^{65}$, meteorología y a tener conocimientos de arquitectura ${ }^{66}$, disciplinas de las que hizo frecuente uso para ilustrar su pensamiento y labor pastoral.

También conviene referir la enseñanza cercana de su hermano Basilio, quien además de conocer las indicaciones de Orígenes, había vivido intensamente la relación con la cultura pagana durante sus estudios en Atenas y Constantinopla; por ello, no desconocía los peligros de la literatura clásica, en el plano moral, y sabía aprovechar los escritos de los autores paganos, a quienes confería tan solo un valor propedéutico a la fe cristiana. ${ }^{67}$

La referencia directa a la virtud fue, tanto para Basilio como para Gregorio, el fundamento y criterio para entrar en diálogo con la cultura pagana, que se vería reforzado con el estudio juicioso y profundo de la Biblia y de autores como Orígenes ${ }^{68}$ (con su exégesis alegórica), Filón de Alejandría (de quien Basilio tomó la idea de hacer de Moisés paradigma del itinerario del alma hacia Dios y la división del libro en his-

${ }^{62}$ Quasten, Patrología II, 132; Trevijano Etchevarria, Patrología, 206; Campenhausen, Los padres de la Iglesia, I, 146.

${ }^{63}$ Marrou, Histoire de l'éducation dans l'Antiquité, 292; Blázquez, La Academia de Atenas como foco de formación humanistica para paganos y cristianos, 609; Moreschini, I Padri Cappadoci, 27.

${ }^{64}$ Dice Campenhausen: "Gregorio estudió, aparte de los escritos de su hermano, a muchos autores clásicos, en particular a Platón, Plotino y otros filósofos platonizantes; pero también a Filón y, de entre los cristianos, ante todo a Orígenes. De los representantes de la cultura griega clásica que le son contemporáneos admira especialmente a Libanio, retórico pagano." (Campenhausen, Los padres de la Iglesia, I, 146.

${ }^{65}$ Daniélou, Le IV siecle, 34-35.

${ }^{66}$ Teja, "Gregorio de Nisa, arquitecto y empresario. Epístola 25”, 67-68.

${ }^{67}$ Balderas Vega, Jesús, cristianismo y cultura en la Antigüedad y en la Edad Media, 186.

${ }^{68}$ Según Moreschini, algunos aspectos del pensamiento de Gregorio corresponden a la gran tradición platónica elaborada por los pensadores cristianos de Alejandría, como Clemente y Orígenes (Moreschini, I Padri Cappadoci, 32). 
toria y teoría), Metodio de Olimpo y Basilio de Ancira, entre otros. A este estudio Basilio se dedicó particularmente durante su estancia en la rivera del rio Iris, donde consolidaba una nueva experiencia monacal.

El Niseno conservó, a lo largo de su vida, un gusto muy vivo por la retórica, y se mostró entusiasta de las obras del famoso rétor pagano Libanio, con quien mantuvo correspondencia (Ep. 13 y 14 $4^{69}$ ) y quien afirmaba que "el que es orador es capaz de ayudar" ${ }^{70}$ Esta frase tuvo que hacer eco en la manera como Gregorio orientó la función de rétor en su ministerio episcopal.

Al mismo tiempo, manifestó un sentido muy vivo de la trascendencia divina que orientó su experiencia vital y la manera como consolidó su teología. Bajo la influencia del pensamiento platónico cristianizado por la Biblia, él concentró todo el género humano en el Logos hecho carne, en vista de la deificación de todos, pero Gregorio no pensó en la idea del Verbo, sino en su persona encarnada. ${ }^{71}$

\section{El Niseno recibió la influencia de la cultura propia de su tiempo}

Gregorio de Nisa fue un hombre de su época, y su manera de pensar y de escribir se circunscribió a los cánones propios de su tiempo. Ya mencionamos la importancia de la retórica en la vida de Gregorio, quien a pesar de no haber sido formado por grandes maestros, profundizó en el tema, estudiando los libros de esta materia, en especial el De Corona de Demóstenes, y sostuvo comunicación con maestros reconocidos. ${ }^{72}$

Basilio inculcó en su hermano el gusto por la literatura griega, lo cual permitió que este se familiarizara con los autores y corrientes vigentes en su contexto: Platón (Fedro, Fedón, República), Aristóteles, Plotino, Porfirio, Posidonio, Jámblico y los estoicos. Ahora bien, muchos de los postulados que Gregorio tomó de estos autores y corrientes, en ese momento histórico habían pasado a ser patrimonio común de la cultura $^{73}$; con esta, Gregorio se mantuvo en sintonía, pero a la vez se puso por encima de ella y fue capaz de verla como algo extraño. ${ }^{74}$

\footnotetext{
${ }^{69}$ Silvas, Gregory of Nyssa: The Letters, 154-155.

${ }^{70}$ Libanio, “Epístola 1544F”, citado por Teja, Emperadores, obispos, monjes y mujeres, 89.

${ }^{71}$ Philips, Inhabitación trinitaria y gracia, 37-38.

${ }^{72}$ Meredith, "Traditional Apologetic in the Contra eunomium of Gregory of Nyssa”, 315-319; Daniélou, Le IV siecle, 24.

${ }^{73}$ Ver Gran Enciclopedia Rialp. Humanidades y Ciencia, http://www.canalsocial.net/ger/ficha_GER. asp?id=1444\&cat=biografiasuelta (consultado el 2 de abril de 2013).

${ }^{74}$ Jaeger y Frost, Cristianismo primitivo y paideia griega, 116.
} 
Si bien los grandes pensadores de su época -ya fueran teólogos, filósofos paganos o retóricos- influyeron en Gregorio, es oportuno afirmar que influencia no significó servidumbre, pues Gregorio evidenció total libertad respecto de autores o corrientes, ya que su mirada estuvo puesta en la búsqueda de la verdad. ${ }^{75}$ Por tanto, él no fue un compilador, sino un intelectual que, si bien reconocía los aportes que otros habían realizado, siempre iba más allá, superándoles en la perspectiva y el alcance de sus postulados. ${ }^{76}$

Además, la influencia no estuvo dada solo por autores y corrientes, sino también por el ambiente vital que llevó a Gregorio a plantearse las preguntas que eran objeto de reflexión, o al menos inquietaban al común de las personas, es decir, el sentido de la vida, la plenitud del ser hombre, el anhelo de la inmortalidad. Por tal razón, la moral acapararía progresivamente su atención. Los demás problemas, políticos, jurídicos o sociales, habrían de ser tratados solo en función de esta moral del destino personal.

Esta sintonía de Gregorio de Nisa con el ambiente vital ayudó al proceso de gestación de un nuevo concepto de ser humano que, en el contexto helénico, implicó un cambio radical de la percepción de la vida, que no en vano se constituyó en una aportación fundamental del cristianismo en el siglo IV.

En efecto, el ideal de vida cristiana después de las persecuciones y del fin del largo periodo de martirio cambió en función de las nuevas condiciones del Imperio: del énfasis en la santidad centrada en el martirio se pasó al énfasis en la santidad centrada en la virtud, que tuvo su primer referente en la vida monástica, y los primeros santos en los miembros de la jerarquía eclesiástica. ${ }^{77}$

\section{La formación del hombre, paideia}

Según Jaeger, la cultura griega -además de haber sido la primera en dejar constancia de la preocupación por la formación del hombre- se desarrolló transformando sus bases previas, no destruyéndolas. En este sentido, el modelo que había venido empleándose hasta entonces no era arrojado como inservible, sino renovado, rigiéndose por la ley de

\footnotetext{
${ }^{75}$ Según Quasten, el gran mérito de la investigación llevada a cabo por Daniélou sobre las relaciones de Gregorio con Platón sigue siendo el haber demostrado, por una parte, la dependencia literaria, pero, por otra, la completa metamorfosis cristiana del pensamiento de Platón (Quasten, Patrología II, 317).

${ }^{76}$ Idem, Le IV siecle, 32-33. Jean Daniélou, quien fue estudioso de la obra de Gregorio, reconoce la dificultad para identificar la influencia de autores y corrientes filosóficas en Gregorio debido a que él no cita casi nunca a los pensadores paganos y, por ello, es en el estudio de los textos donde nosotros podemos esperar alguna luz. Idem, Orientations actuelles de la recherche sur Grégoire de Nysse, 3-17.
}

${ }^{77}$ Alfaro Giner y Blasco, Espacios de infertilidad y agamia en la Antigüedad, 123. 
la estricta continuidad. ${ }^{78}$ La filosofía de Platón es ejemplo de ello al buscar reintegrar los periodos anteriores de la cultura helénica. En efecto -afirma Jaeger-, "Platón recoge deliberada y sistemáticamente, los diversos problemas del periodo preplatónico y los lleva a un plano filosófico más elevado" ${ }^{79}$

Entre estos problemas se ubica el de la paideia, que fue convirtiéndose en expresión auténtica de los afanes espirituales en tiempos de Platón. La paideia era entendida como el despertar a un ideal consciente de educación y de cultura, que se había ido gestando por la mediación de la filosofía, la ciencia y, en lucha constante con ellas, el poder formal de la retórica. ${ }^{80}$ Platón, marcado por la experiencia vivida junto a su maestro Sócrates, vería en su figura el eje de la formación del hombre griego por su propio esfuerzo. ${ }^{81}$

La noción de paideia forjada en el siglo IV a.C., que se concibe como resultado en el cual confluye el hombre mismo, que alcanza la estatura perfecta y los elementos modeladores con los que tal logro es obtenido, se mantuvo en los siglos venideros, y con ella se encontraron los autores cristianos de los primeros siglos, en su diálogo con la cultura griega. Particularmente fueron los padres griegos, entre ellos, Justino, Clemente, Orígenes y los capadocios, en su mayoría pertenecientes a la escuela de Alejandría, quienes contribuyeron a un renacimiento de la cultura griega. ${ }^{82}$

La importancia de la filosofía en esta época tiene una de sus expresiones más cualificadas en el concepto de paideia. El cristianismo alejandrino usaría esta cultura como base de su reflexión, pero transformándola en paideia cristiana, cuya fuente sería el Logos divino, del que tanto griegos como bárbaros serían instrumentos; de esta manera se negó todo valor a la religión pagana, aunque se admitió la importancia de su cultura. ${ }^{83}$

\footnotetext{
${ }^{78}$ Jaeger y Frost, Cristianismo primitivo y paideia griega, 376.

${ }^{79}$ Ibid., 374.

${ }^{80}$ Ibid., 383.

${ }^{81}$ En efecto, según Heinrich Maier, "la grandeza peculiar de un Sócrates no puede medirse con la pauta de un pensador teórico. Hay que considerarlo como el creador de una actitud humana que señala el apogeo de una larga y laboriosa trayectoria de liberación moral del hombre por sí mismo y que nada podría superar: Sócrates proclama el Evangelio del dominio del hombre sobre sí mismo y de la 'autarquía de la personalidad moral" (citado por Jaeger, Cristianismo primitivo y paideia griega, 402).

${ }^{82}$ En palabras de Jaeger, "los ideales culturales griegos y la fe cristiana se mezclaron, por muy ansiosos que estemos de conservar inmaculados unos y otra. Había, en ambas partes, un intenso deseo de penetración mutua, sin tener en cuenta, por ahora, lo reacios a asimilarse que eran estos dos lenguajes, cada uno de los cuales tenía sus diferentes maneras de sentir y de expresarse a sí mismo en forma metafórica" (Jaeger, Cristianismo primitivo y paideia griega, 61-62).
}

${ }^{83}$ Uribarri, Contexto y nueva evangelización, 87-88. 
Concretamente, con Gregorio de Nisa ${ }^{84}$, el cristianismo alcanzó el punto en el que sacó sus propias conclusiones de la gran experiencia griega expresada en la idea de paideia, y le fue posible comprender aspectos centrales del verdadero significado de la misma ${ }^{85}$, entendida como perfección del alma que no solo se circunscribe a esta vida, sino que continúa por toda la eternidad. ${ }^{86}$

Para el Niseno, la educación es un proceso formativo de la personalidad concebida como morphosis, cuyo ideal pedagógico cristiano reposa sobre la paideia, en el sentido de la naturaleza plástica del alma, donde se esculpen "formas" que la embellecen y desarrollan su personalidad. ${ }^{87}$

Dicha paideia evoca la metáfora del crecimiento gradual del ser espiritual humano y su analogía con la naturaleza física del hombre; sin embargo, la nutrición del alma es diferente a la del cuerpo al requerir un cuidado constante. ${ }^{88}$ Ahora bien, al ser la educación un proceso de moldeamiento o formación, el objeto de aprendizaje tiene la función de molde que da forma al sujeto.

El molde de la paideia griega, en su primer momento, fueron los héroes de Homero; posteriormente, los sofistas añadieron las artes liberales; finalmente, Platón concibió la filosofía como la paideia superior. ${ }^{89}$ Para Gregorio, la paideia cristiana es la Biblia y su molde es Cristo. En ello se resumen los ideales más altos de la vida humana, y Cristo es la imagen ideal o el gran paradigma del hombre..$^{90}$

En este sentido, la paideia del cristiano es la imitatio Christi, cuya morphosis se plasma cuando Cristo toma forma en él. En dicho proceso formativo, el Espíritu Santo se convierte en una fuerza educadora que habla por medio de los seres humanos y los conduce a la adquisición de las virtudes.

En este caso, el perfeccionamiento humano es posible por la ayuda y la gracia divina, concebida como la cooperación del Espíritu Santo con el esfuerzo humano. Dicha cooperación se entiende debido a que el Niseno no le menoscaba potencialidad

\footnotetext{
${ }^{84}$ Jaeger, Cristianismo primitivo y paideia griega, 122.

${ }^{85}$ Armstrong, Una historia de Dios, 553.

${ }^{86}$ Esta idea la toma Gregorio del mito de Er, de Platón, que se encuentra en el libro X de la República (Jaeger, Cristianismo primitivo y paideia griega, 124).

${ }^{87}$ Ibid., 121-122. Según Jaeger, Gregorio de Nisa comprendió la paideia griega "como proceso formativo de la personalidad humana, que los grandes educadores griegos habían distinguido en forma tajante de la sustancia sine qua non del proceso educativo" (ibid., 121).

${ }^{88}$ Ibid., 123.

${ }^{89}$ Ibid., 127.

${ }^{90}$ Ibid., 129.
} 
a lo humano para su desarrollo espiritual, intelectual y moral; incluso considera que el auxilio divino se incrementa en proporción al esfuerzo humano. ${ }^{91}$

Para Gregorio, el cristianismo no es tan solo un conjunto de dogmas, sino esencialmente una "contemplación de Dios y una unión cada vez más perfecta con él. Es la deificatio, y el camino a ella es la paideia, la Anábasis divina". ${ }^{92}$ Además, considera que la religión de Cristo es una forma de vida, a la que denomina "vida filosófica", entendida de acuerdo con un género de vida ascética que seguía ideales monásticos.

Este acercamiento a la categoría paideia nos permite ver con evidencia que la estructura de la teología del Niseno está permeada por la idea griega de paideia, sobre todo, en su forma platónica, en la cual la paideia deriva del nous divino. Para el Niseno, la educación filosófica griega ofrecía una analogía completa con la teología cristiana, tal como ella la entendía; por eso -considera Jaeger ${ }^{93}$ - usó las formas griegas como modelo estructural de una cultura completamente desarrollada, y por medio de la comparación creó -respecto a cada una de ellas- una variante cristiana conformada en el molde clásico, pero a la vez muy claramente diferente a él.

\section{Antecedentes próximos de la inculturación de la teología en Gregorio de Nisa}

\section{Ejercicio pastoral y literario: un hombre de total libertad y espíritu creativo}

Después de haber acogido los consejos de sus hermanos y su amigo Gregorio de Nacianzo, el Niseno se unió a la experiencia monástica en el Ponto, donde-como señalamos antes- estuvo dedicado al estudio de las Sagradas Escrituras y de las obras de Orígenes, entre otros. Durante esta estadía, su hermano Basilio fue elegido obispo metropolitano (370), en reemplazo de Eusebio de Cesarea, a pesar de las intrigas de algunos obispos cercanos al arrianismo que estaban en su contra.

Esta elección hizo que Basilio viera la necesidad de rodearse de personas con buena formación, para mantener firme la fe de Nicea y hacer frente a las diferencias con los arrianos y a las políticas imperiales. En esta circunstancia, Gregorio fue consagrado obispo de la pequeña ciudad de Nisa ${ }^{94}$ (371). Esto le brindó una nueva experiencia

\footnotetext{
${ }^{91}$ Ibid., 123-124.

${ }^{92}$ Ibid., 125-126.

${ }^{93}$ Ibid., 136.

${ }^{94}$ Wace, y Schaff, A Select Library of Nicene and Post Nicene Fathers of the Christian Church. Vol. V. Gregory of Nyssa: Dogmatic Tratises, etc.; Mateo Seco, Gregorio de Nisa, Vida de Macrina. Elogio de Basilio, 10.
} 
en la que, si bien se le cobraría su ingenuidad administrativa, se pudo poner al tanto de los problemas eclesiales y eclesiásticos del momento e implicarse en la resolución de los mismos, no sin enfrentar dificultades, que no tardaron en aparecer.

Por este tiempo, el emperador Valente, quien era afín al arrianismo, persiguió a los obispos que defendían la fe de Nicea: cualquier pretexto servía para deponer a un obispo que no fuese arriano. Concretamente, en los primeros meses de 375, Gregorio fue víctima de las marrullerías eclesiásticas de los obispos arrianos, quienes le acusaron de dilapidar los bienes de la Iglesia, y al año siguiente un Sínodo de obispos filoarrianos reunidos en Nisa lo despojó de su sede.

Ante este hecho, su hermano Basilio consiguió hacerle huir y le escondió en un lugar seguro, no sin reprocharle antes la ingenuidad que había mostrado frente a las tretas e intenciones mezquinas de los arrianos. ${ }^{95}$ Solo con la muerte del emperador Valente, acaecida en 378, pudo Gregorio regresar a la sede de Nisa, donde fue acogido calurosamente por el pueblo, tal como lo cuenta en la Carta 6, dirigida al obispo Ablabius. ${ }^{96}$

En 379, tras la muerte temprana de Basilio, Gregorio sintió la necesidad de continuar el legado de su hermano, asumió un papel más determinante en la Iglesia y desplegó una intensa actividad pastoral, tanto en lo concerniente a la parte administrativa, tomando parte activa en sínodos y $\operatorname{concilios}^{97}$, como en la defensa de la fe de Nicea y en la consolidación del dogma trinitario. De ahí que fuera designado por Teodosio como uno de los representantes de la fe ortodoxa, después del Concilio de Constantinopla, en $381 .^{98}$

Respecto del tema de la producción literaria, es significativa la manera como los estudiosos de la patrística y de la antigüedad cristiana se refieren a Gregorio, pues interpretan dicha producción argumentando -como hace Von Balthasar ${ }^{99}$ - que su trabajo sobrepasa el de Gregorio de Nacianzo, Basilio y Orígenes, por la profundidad

\footnotetext{
${ }^{95}$ Campenhausen, Los padres de la Iglesia I, 148.

${ }^{96}$ Silvas, Gregory of Nyssa: The Letters, 142.

${ }^{97}$ El Sínodo de Antioquía, en 379; desempeñar comisiones sinodales como la de Arabia, en 380; viajar en ese mismo ańo a Ibora y Sebaste para arreglar la sucesión del obispo, en donde es elegido arzobispo; tomar parte activa en el segundo Concilio Ecuménico de Constantinopla, donde impartió el discurso inaugural y fue comisionado para restablecer el orden eclesiástico en la provincia de Arabia (Quasten, Patrología II, 283).

${ }_{98}$ Campenhausen, Los padres de la Iglesia I, 152; Trevijano Etchevarria, Patrologí, 207; Daniélou, Le IV siecle, 8.

${ }^{99}$ Von Balthasar, Présence et pensée. Essai sur la philosophie religeuse de Grégoire de Nysse, xiii-xiv.
} 
de su pensamiento y por la forma de traducir la herencia espiritual de la antigua Grecia al modo cristiano.

Jesús Balderas ${ }^{100}$ afirma que Gregorio es el escritor más versátil, que sus libros revelan profundidad de pensamiento, gran capacidad de adaptación y comprensión de las corrientes contemporáneas de la vida intelectual. Quasten, Trevijano y Hamman ${ }^{101}$ enfatizan en su talante especulativo y místico, que le permitió sistematizar de manera orgánica la fe y consolidar una teología mística.

Ahora bien, en la producción literaria de Gregorio se pueden distinguir -según Daniélou $^{102}$ - tres momentos: desde 370 hasta antes de la muerte de su hermano Basilio, en enero de 379; entre enero de 379 y 385; y después de 385.

En dicha producción se encuentran tratados dogmáticos, en su mayoría polémicos, contra las herejías de su tiempo; obras exegéticas que ponen en evidencia la continuidad de los principios hermenéuticos de Orígenes; obras ascéticas que consolidan una doctrina sobre la espiritualidad; discursos y sermones que exhiben gran variedad de temas que evidencian la afición por la ornamentación retórica; y cartas que dan idea de la variedad de los intereses y de las relaciones de Gregorio. ${ }^{103}$

Según Quasten ${ }^{104}$, en el estilo literario de Gregorio se evidencia más la incidencia de la segunda sofística y mantiene una permanente tensión entre razón y fe. En la selección de las palabras sigue a sabiendas a los autores clásicos y hace uso de la koiné y de los Setenta. Muestra preferencia por la ecphrasis y la metáfora, por los juegos de palabras, paradojas y oxymoron, que reflejan la influencia de la retórica griega de su tiempo. En sus panegíricos y discursos fúnebres, y especialmente en sus tratados polémicos, su dicción aparece llena de fuego y energía, pero adolece con frecuencia de excesivo pathos y ampulosidad.

En cuanto al método presente en su trabajo escriturístico, Quasten ${ }^{105}$ afirma que Gregorio prestó más atención que Basilio y Gregorio Nacianceno a la ratio theologica, entendida como función del pensamiento puramente racional.

${ }^{100}$ Balderas Vega, Jesús, cristianismo y cultura en la antigüedad y en la Edad Media, 173.

${ }^{101}$ Quasten, Patrología II, 315-316; Trevijano Etchevarria, Patrología, 206; Hamman, Guía práctica de los padres de la Iglesia, 186. Daniélou considera a Gregorio de Nisa como el fundador de la teología mística (Daniélou, Platonisme et théologie mystique. Essai sur la doctrine spirituelle de saint Grégoire de Nysse, 7).

${ }^{102}$ Idem, "La chronologie des oeuvres de Gregoire de Nysse”, 159-166.

${ }^{103}$ Quasten, Patrología II, 286-315.

${ }^{104}$ Ibid., 283-284; Franceschini, Manuale di patrologia, 280-282.

${ }^{105}$ Quasten, Patrología II, 317. 
Daniélou $^{106}$, Drobner ${ }^{107}$ y Ojell ${ }^{108}$ plantean que el método lo constituye la akolouthia, que representa un leitmotiv de su pensamiento y es entendida como una coherencia, secuencia de racionamientos de carácter explicativo y argumentativo que aseguran el carácter científico del conocimiento mediante la reducción a los primeros principios. Particularmente Ojell afirma que la akolouthia estaba basada en la noción de secuencia necesaria entre la causa y los efectos, y la conexión de cosas, fenómenos o argumentos y que era usada por Gregorio en la exégesis bíblica, en la lógica, en la cosmología, en la historia, en la filosofía moral y en la ética.

Akolouthia era el método que Gregorio utilizaba, tanto para explorar la secuencia lógica y conectividad de pensamientos como para expresar pensamientos de una manera lógica y coherente en sus escritos: los mismos principios metodológicos -de los cuales es muy consciente Gregorio- aplicarán en ambos casos. Por esta razón, cuando con el objetivo de analizar e interpretar a Gregorio lo más lejos posible, según su intención, es importante interiorizar su método y sus principios. Interiorizar el método de Gregorio es la manera más adecuada para familiarizarse con su intención también. ${ }^{109}$

Ahora bien, es importante señalar que esas dos formas como el Obispo de Nisa entiende el método permiten comprender su convicción de hacer uso de la razón para probar, hasta dónde fuese posible, los misterios de la revelación. Sin embargo, en todos estos esfuerzos por profundizar en la fe por medio de la inteligencia se deja guiar por la tradición de los padres. ${ }^{110}$

\section{Conclusión}

Después del recorrido realizado es posible retomar nuevamente el objetivo trazado de identificar las características y los ejes fundamentales que orientaron la labor de inculturación del quehacer teológico de Gregorio de Nisa en la cultura griega, y que

${ }^{106}$ Daniélou, L 'essere e il tempo in Gregorio di Nissa, 30, 46. En el libro El misterio de la historia, Daniélou señala que Gregorio recibió el término akolouthia de la filosofía griega, particularmente de Aristóteles, pero el uso que le dio lo orientó en función de dar razón del desarrollo progresivo del plan de Dios en el cual el término se comprende como proceso de divinización (Daniélou, El misterio de la historia, 315-316).

${ }^{107}$ Drobner, "Fuentes y métodos filosóficos de Gregorio de Nisa”, 209.

${ }^{108}$ Ojell, One Word, One Body, One Voice: Studies in Apophatic Theology and Christocentric Anthropology in Gregory of Nyssa, 33-42.

${ }^{109}$ Ibid., 34. La traducción es nuestra.

${ }^{110}$ Tal como afirma en el $A d$ Ablabium: "Si es que nuestro razonamiento no está a la altura del problema, hemos de mantener siempre firme e inmóvil la tradición que hemos recibido de los padres por sucesión." (Migne, Patrologiae. Cursus Completus, 117). La traducción es de Alberto Múnera. 
permiten una mejor comprensión de su obra. A continuación señalaremos, en pocas palabras, el alcance del trabajo realizado.

En primer lugar, el contexto de la Capadocia, en el siglo IV, permite comprender que el trabajo de inculturación es hijo de su tiempo: los factores sociales, políticos, económicos, culturales y eclesiásticos fueron determinantes en el modo de existencia que de Gregorio de Nisa y su madurez intelectual y de fe. Esto, a su vez, le permitió sistematizar su propia experiencia vital, referida a la experiencia de personajes bíblicos (Cristo, Pablo, Moisés) y cercanos a su experiencia familiar (Gregorio Taumaturgo, Macrina, Basilio) que permean su obra literaria.

En segundo lugar, la experiencia familiar fue determinante en la forma como Gregorio encarnó la fe cristiana, pues estuvo marcada por la vivencia del martirio de uno de sus abuelos, la santidad de su abuela Macrina, la piedad de sus padres y el testimonio directo de su hermana Macrina (la joven) y de su hermano Basilio, a quienes identificó como modelos de virtud y a quienes dedicó un panegírico. Sin embargo, este núcleo familiar no solo le permitió apropiar la fe, sino también -dado el ambiente de cercanía con la cultura griega en que vivió la familia- establecer, en su propia persona y posteriormente en sus obras, un diálogo entre razón y fe.

En tercer lugar, aunque Gregorio de Nisa no tuvo la posibilidad de acceder a los estudios a la manera de su hermano Basilio, sí contó con una buena iniciación, por parte de su padre, que era rétor, con el aporte de las escuelas que por el momento había en Cesarea; pero ante todo contó con el aporte de su hermano Basilio (de quien siempre se refería como su maestro), quien le puso en contacto con las obras de los autores clásicos, tanto filósofos como teólogos, y le facilitó la comunicación con el rétor Libanio, a quien prodigó gran estima. El amor de Gregorio por la ciencia, el conocimiento y la reverencia por la fe se conjugaron, de manera tal, que hicieron posible la consolidación de la doctrina cristiana de gran rigor y valor que se refleja en sus escritos.

En cuarto lugar, la apertura a la cultura de su tiempo permitió a Gregorio asimilar críticamente los elementos más representativos de la misma y enriquecerse a la manera de los israelitas que, al salir de Egipto, tomaron los vasos de oro y plata, lo cual el Niseno interpretó como un acto de aprovisionarse con la cultura extranjera. Además, se sintonizó con el ambiente vital de ese entonces, que acentuaba en las prácticas ascéticas, en la preocupación por el sentido de la vida y la perfección de la vida, y por esta razón, en la vida virtuosa, que se traducía en la centralidad del tema moral a partir del cual se abordaban los demás temas y problemas.

Entre los elementos representativos de la cultura griega, Gregorio asumió la idea de paideia griega, sobre la cual estructuró y desarrolló su teología, para dar lugar a la paideia cristiana. Para ello aprovechó algunos aportes que estaban presentes en la 
tradición, concretamente en Clemente y Orígenes.

En quinto lugar, la obra literaria de Gregorio no se entiende sin la referencia al método utilizado, que recibe el nombre de akolouthia. Este permite evidenciar la agudeza de sus razonamientos al servicio de la búsqueda de la verdad o de los primeros principios que ayudan a desocultar el fundamento invisible presente en la realidad.

La particularidad de su método facilita la comprensión del uso que Gregorio hizo de los elementos de la filosofía. Estos, en su mayoría, hacían parte de la cultura de su época y fueron apropiados con tal libertad que sufrieron una metamorfosis, debido a que el uso no fue indiscriminado sino que apuntó a argumentar en favor de la fe y de la interpretación de la Escritura. Esta constituye la piedra de toque de su labor teológica.

\section{Bibliografía}

Alfaro Giner, C. y A. Blasco. Espacios de infertilidad y agamia en la Antigüedad. Valencia: Sema, 2007.

Argüello, J. Caminar con los padres de la Iglesia. Managua: Graphic, 2006.

Armstrong, K. Una historia de Dios. Barcelona: Paidós, 2006.

Azevedo M. Comunidades eclesiais de base e inculturação da fé. São Paulo: Loyola, 1986.

Backhouse, E. y C. Tyler. Historia de la Iglesia primitiva. Desde el siglo I hasta la muerte de Constantino. Barcelona: Clie, 2004.

Balderas Vega, G. Jesús, cristianismo y cultura en la Antigüedad y en la Edad Media. México: Universidad Iberoamericana, 2007.

Blázquez, J.M. "La Academia de Atenas como foco de formación humanística para paganos y cristianos. Los casos de Juliano, Basilio y Gregorio Nacianceno." Gerión 19 (2001): 595-628.

Campenhausen, H. V. Los padres de la Iglesia. I. Padres griegos. Madrid: Cristiandad, 1967.

Codina, V. Los caminos del Oriente cristiano. Iniciación a la teología oriental. Santander: Sal Terrae, 1997.

Concilio Vaticano II. "Constitución pastoral Gaudium et spes sobre la Iglesia en el mundo actual." En Constituciones, decretos, declaraciones del Concilio Vaticano II, 113-225. Madrid: Biblioteca de Autores Cristianos, 1966.

Congregación para la Educación Católica. "Instrucción sobre el estudio de los padres 
de la Iglesia." Vatican, http://www.vatican.va/roman_curia/congregations/ ccatheduc/index_sp.htm http://www.vatican.va/roman_curia/congregations/ ccatheduc/index_sp.htm (consultado el 2 de abril de 2013).

Daniélou, J. El misterio de la historia. San Sebastian: Dinor, 1957.

. L'essere e il tempo in Gregorio di Nissa. Roma: Arkeios, 2000.

. "La chronologie des oeuvres de Gregoire de Nysse." Studia Patristica 7 (1966): 159-169.

. Le IV siecle. Gregoire de Nysse et son milieu. Paris: Institut Catholique, 1964.

. "Le mariage de Grégoire de Nysse et la chronologie de sa vie." Revue d'Études Augustiniennes 2 (1956): 71-78.

. "Orientations actuelles de la recherche sur Grégoire de Nysse." En Écriture et culture philosophique dans la pensée de Grégoire de Nysse. Actes du Colloque de Chevetogne (22-26 september 1969), editado por Marguerite Harl y E.J. Brill, 3-17. Leiden: M. Harl, 1971.

. Platonisme et théologie mystique. Essai sur la doctrine spirituelle de saint Grégoire de Nysse. París: Aubier, 1944.

De Franca Miranda, M. La inculturación de la fe: un abordaje teológico. Bogotá: Celam, 2004.

Drobner, H. R. "Fuentes y métodos filosóficos de Gregorio de Nisa." Teología y vida Vol. XLIII, No. 2-3 (2002): 205-215.

Eliade, M. Historia de las creencias y de las ideas religiosas. III. De Mahoma a la era de las reformas. Barcelona: Paidós, 1999.

Fernández Urbina, J. Historia del cristianismo. Tomo I. Constantino y el triunfo del cristianismo en el Imperio Romano. Madrid: Trotta, 2003.

Franceschini, P.G. Manuale di patrologia. Milano: Ulrico Hoepli, 1919.

Grégoire de Nysse. Vie de Sainte Macrine. SC 178. Paris: Du Cerf, 1971.

Grégoire le Thaumaturge. Remerciement a Origène suivi de la lettre d' Origène a Grégoire. SC 148. Paris: Du Cerf, 1969.

Gregorio de Nisa. Vida de Macrina. Elogio de Basilio. Biblioteca de Patrística 31. Madrid: Ciudad Nueva, 1995.

. Vita di Gregorio Taumaturgo. Testi Patristici. Roma: Citta Nuova, 1998.

Gutiérrez, G. Teología de la liberación. Salamanca: Sígueme, 1972. 
Hamman, A. Guía práctica de los padres de la Iglesia. Bilbao: Desclée de Brouwer, 1968. . Para leer los padres de la Iglesia. Bilbao: Desclée de Brouwer, 2009.

Heidegger, M. Carta sobre el humanismo (2a.ed.). Madrid: Taurus, 1966.

. "Fenomenología y teología." En Hitos, por M. Heidegger, 49-74. Alianza: Madrid, 2000.

Jaeger, W. y E.C. Frost. Cristianismo primitivo y paideia griega. Breviarios del FCE 182. México: Fondo de Cultura Económica, 1974.

Jones, A.H.M. The Cities of the Eastern Roman Provinces. Oxford: Wipf \& Stock Publishers, 2004, 1971.

Kopecek, Th. A. "The Social Class of the Cappadocian Fathers." Church History: Studies in Christianity and Culture Vol. 42 (1973): 461-466.

Laurent, B. Iniciación a la práctica de la teología. La práctica, acciones pastorales. Madrid: Cristiandad, 1983.

Libanio, J.B. y A. Murad. Introducción a la teología. Perfiles, enfoques, tareas. Sao Paulo: Ediciones Loyola, 1996.

Llorca, B. Historia de la Iglesia Católica. Edad Antigua. Madrid: Biblioteca de Autores Cristianos, 1976.

Lonergan, B. Método en teología (4a. ed.). Salamanca: Sígueme, 2006.

López, E. La evangelización como práctica interpretativa. Bogotá: Pontificia Universidad Javeriana, 2008.

Malherbe, A. J. y E. Ferguson. Gregory of Nyssa. The Life of Moses. New York: Paulist Press, 1978.

Marrou, H.I. Histoire de l'éducation dans l'Antiquité. Paris: Seuil, 1948.

Mateo Seco, L.F. Gregorio de Nisa. Sobre la Vida de Moisés. Biblioteca de Patrística 23. Madrid: Ciudad Nueva, 1993.

- Gregorio de Nisa: Vida de Macrina. Elogio De Basilio. Biblioteca de Patristica 31. Madrid: Ciudad Nueva, 1995.

Meredith, A. "Traditional Apologetic in the Contra eunomium of Gregory of Nyssa." Studia Patristica 14 (1976): 315-319.

Migne, J. P. Patrologiae. Cursus completus. Series Graeca Vol. 45. Paris: s/e, 1863.

Moreno Martínez, J.L. La luz de los padres. Temas patrísticos de actualidad eclesial. 
Toledo: Instituto Teológico San Ildefonso, 2005.

Moreschini, C. I Padri Cappadoci, storia, letteratura, teología. Roma: Città Nuova, 2008.

Morin, E. Los siete saberes indispensables para la educación del futuro. Bogotá: Ediciones del Ministerio de Educación Nacional, 1996.

Ojell, A. One Word, One Body, One Voice: Studies in Apophatic Theology and Christocentric Anthropology in Gregory of Nyssa. Helsinki: University of Helsinki, 2007.

Orlandis, J. Historia breve del cristianismo. Madrid: Rialp, 1999.

Philips, G. Inhabitación trinitaria y gracia. Salamanca: Secretariado Trinitario, 1980.

Poupard, Paul. "Los padres de la Iglesia: actualidad de una inculturación de la fe." En El diálogo fe-cultura en la antigüedad cristiana, dirigido por Domingo Ramos Lisson, 27-46. Pamplona: Ediciones Eunate, 1996.

Quasten, J. Patrología. I. Hasta el Concilio de Nicea. Madrid: Biblioteca de Autores Cristianos, 1973.

. Patrología. II. La edad de oro de la literatura patrística griega. Madrid: Biblioteca de Autores Cristianos, 1973.

Ramos Jurado, E. A. "Paideia griega y fe cristiana en Sinesio de Cirene." Habis 23 (1992): 247-261.

Rovira Belloso, J. M. Introducción a la teología. Madrid: Biblioteca de Autores Cristianos, 1996.

Silvas, A. M. Gregory of Nyssa: The Letters. Introduction, Translation and Commentary. Supplements to Vigiliae Christianae Vol. 83. Boston: Brill Leiden, 2007.

Standaert, N. "L'histoire d'un néologisme. Le terme 'inculturation' dans les documents romains." Nouvelle Revue Theologique 110 (1988): 555-570.

Teja, R. Emperadores, obispos, monjes y mujeres, protagonistas del cristianismo antiguo. Madrid: Trotta, 1999.

. "Gregorio de Nisa, arquitecto y empresario. Epístola 25.” Antigüedad y cristianismo 8 (1991): 67-68.

Torres Moreno, E. San Gregorio de Nisa. "De Vita Moysis": estudio estructural. Madrid: Universidad Complutense, 2005.

Trevijano Etchevarria, R. Patrología. Madrid: Biblioteca de Autores Cristianos, 1994.

Uribarri, G. Contexto y nueva evangelización. Madrid: Universidad de Comillas, 2007. 
Von Balthasar, H.U. Présence et pensée. Essai sur la philosophie religeuse de Grégoire de Nysse. Paris: Beauchesne, 1942.

Wace, H. y Ph. Schaff. A Select Library of Nicene and Post Nicene Fathers of the Christian Church. Vol. V. Gregory of Nyssa: Dogmatic Tratises, etc. New York: Oxford, 1793. 